\title{
Mass loss and release of nutrient from empty fruit bunch of oil palm applied as mulch to newly transplanted oil palm
}

\begin{abstract}
Applying a mulch of oil palm empty fruit bunches (EFBs) from processing mills to newly transplanted oil palm is widely practiced for sustainable management and recycling of solid waste from the oil palm industry. Thus, it is important to understand the decomposition and mass loss of EFBs and its nutrient release pattern for better fertility management. The present study was conducted in a newly transplanted oil palm field to investigate the mass loss of applied EFBs and nutrient release pattern over a 12-month period. The treatments evaluated in the present study were: (1) chemical fertiliser (CF) application only; (2) EFB application only; and (3) EFB and $\mathrm{CF}$ application $(\mathrm{EFB}+\mathrm{CF})$. The treatments were applied immediately after transplanting 13-month-old palms. EFBs were applied around the base of the oil palm at a rate of $170 \mathrm{~kg} \mathrm{palm}^{-1}$. Results showed that $50 \%$ dry weight of EFB and EFB+CF was lost within 90 days of application. The $\mathrm{C}: \mathrm{N}$ ratio decreased from 82 to 20 after 180 and 172 days in $\mathrm{EFB}$ and $\mathrm{EFB}+\mathrm{CF}$ respectively. The breakdown of lignin in EFBs was found to be significantly accelerated by the introduction of CF. Soil properties were improved by EFB application with an increase in $\mathrm{pH}$, total mineral $\mathrm{N}$ and exchangeable $\mathrm{K}$ of the top soil. After 317 DAP, the soil organic $\mathrm{C}$ content subjected to treatment with EFB only and EFB+CF was significantly higher (i.e. $1.7 \%$ ) when compared with that subjected to the control treatment (i.e., $1.3 \%$ ). Total $\mathrm{N}$ increased significantly from $0.06 \%$ to $0.12 \%$ for both EFB treatments.
\end{abstract}

Keyword: Mass loss and release; Nutrient; Empty fruit bunch of oil palm; Newly transplanted oil palm; Decomposition; Mulching 